\title{
Lauri KOSKELA
}

Raija HYNYNEN

Martti KALLAVUO

Kalle KAHKÖNEN

Jouni SALOKIVI

Laboratory of Building Economics

Technical Research Centre of Finland

\section{Expert Systems}

in Construction

Initial Experiences 


\begin{abstract}
ABSTRAIT
Ce présentation décrit le développement des systèmes experts pour les applications en construction fait à la laboratoire de cout de construction du Centre de Recherche Technique de Finlande. Cinq systèmes de démonstration sont décrits. Les applications sont: réglements contre l'incendie, repeinture des façades en bois, conseils sur les prêts pour rehabilitation, conception des routes et seléction des ingredients de beton. Les expériences faits pendant le développement sont évalués.
\end{abstract}

\title{
ABSTRACT
}

This paper describes development of expert systems for construction applications in the Laboratory of Building Economics at the Technical Research Centre of Finland. Five small prototype or demonstration expert systems are described. These include expert systems for fire regulations, repainting of wooden facades, renovation loan guidance, pavement design and concrete mix selection. Experiences gained in the development work are evaluated. 


\section{Introduction}

The applicability of expert systems in the construction industry has been analyzed in a number of overview reports [Lansdown 1982, Wager 1984]. The general conclusion has been that expert systems provide an interesting and widely useful tool for the construction industry. It is argued, that due to the fragmented and complex nature of the industry, the accumulation and distribution of industrywide know-how and experience has been slow and inefficient. Knowledge engineering is expected to provide a means for such an accumulation and distribution of knowledge.

On a more general level, the proliferation of expert systems is forecast to occur in two waves [Harmon \& King 1985]. In the first wave, rising in these years (1985 and 1986), small expert systems are feasible. In the second wave, ascending in the 1990's, large and versatile knowledge based systems become possible.

Clearly expert systems are an interesting new development for the construction industry. However, it is also an exceptionally young area; the first construction related references are from year 1982. Except for Japan [Koskela 1985], the interest for expert systems related to construction has been evident mostly in academic circles. Hardly anybody in the construction industry has experience of expert systems.

The question addressed in this paper is related to this state of affairs: What can and ought be done in organizations responsible for the development of the construction industry, which totally lack knowledge engineering expertise and powerful AI computers, usually seen as a prerequisite for expert systems activities? Wouldn't it be better to wait for the refinement of the expert systems technology?

The paper is based on experiences and observations from a learning process started in mid 1984 in the Laboratory of Building Economics at the Technical Research Centre of Finland (VTT).

\section{Knowledge engineering research in the Laboratory}

\subsection{Overview}

The first commercial shell, ES/P Advisor, was acquired in September 1984 in order to make acquaintance with the technology. Some demonstration systems and an expert system for building standards were built with this shell. In the summer of 1985 the level of activity was raised, and a voluntary expert system study group was established. Building of renovation loan, repainting and road structure design expert systems was commenced. Another shell, Insight 2, was acquired in the second half of the year. By the end of 1985, a necessary momentum had been accumulated to start greater projects. Thus development of a concrete selection expert system was launched, to be followed by a project concerned with expert systems of construction sites. In January 1986, the next shell, GURU, was bought, to be applied in these new projects. From now on expert system training is offered to all researchers of the Laboratory.

\subsection{Tools}

For a detailed analysis of small expert system tools, see [Allwood 1985].

ES/P Advisor from Expert Systems International (Oxford) is a Prolog-based expert system shell, which is especially suitable for controlled output of text. It is thus appropriate for transforming regulations, laws and manuals into expert systems. Classical propositiona: logic is used for inferencing. The system built can be augmented with Prolog-programmes. However, because of the inherent features of Prolog, this shell is not suitable for applications requiring much numerical calculations. The shell, priced at $£ 600$, runs on IBM PCs and some other computers.

Insight 2 from the Five Level Research, Inc. (Florida) is also meant primarily for IBM PC:s. It is production rule based, with both backward and forward chaining capabilities. The shell includes a knowledge base editor, a Pascal-interpreter and an interface to dBASE II data manage- 
ment software. Probabilistic reasoning is realized through confidence weighting. Insight 2 is considered as one of the best tools for expert system prototyping for micros in its price class (\$495) on the market at the moment [Huomo 1985].

GURU from Micro Data Base Systems, Inc. (Indiana) is a new generation expert system shell. Here an expert system shell is combined with features of the popular integrated software packages: spreadsheet, business graphics, text processing, data base management and communication. GURU is available for IBM PC:s and its price in the USA is $\$ 3000$.

\section{Expert systems applications}

\subsection{Expert systems for building standards}

\subsubsection{Introduction}

Building standards and regulations have been under active development in Finland in the last decades. The great number of organisations which take part in the development is a problem for the usability of the standards. There are many different standards, and the users have difficulties in finding the relevant ones and understanding them.

Building standards include a lot of causal and experimental knowledge. Thus expert system technology is a natural way for representing them in a computerized form. Prototypes of building standards expert systems have been built in Australia [Rosenman 1985], in the United Kingdom and in Finland [Björk 1985].

There are two different viewpoints in developing these systems. Firstly, it is important for building designers to find specific constraints for a particular design problem. Secondly, it is necessary to evaluate design solutions against applicable standards. Thus two kinds of expert systems are needed. The first class consists of advisory systems and the second one of a system for checking designs.

\subsubsection{Representing standards as a knowledge base}

Computer based systems for building standards formulation and representation have been developed in the USA and Australia. The system developed in USA is called SASE (Structural Analysis, Synthesis and Expression of standards) and the one developed in Australia is called AMUBC. With these systems it is possible to build databases of building standards [AMUBC, report 1984], [AMUBC, manual 1984], [Hari is 1981], [Stahl 1983].

Characteristic for the databases of both systems are decision tables. A decision table is a matrix that relates combinations of conditions to combinations of actions. When representing multiple conditions and actions, decision tables are especially useful.

\subsubsection{An expert system prototype based on the Finnish Building Code}

At VTT an expert system prototype has been developed, which assists engineers and architects in using the Building Code in particular design situations. The main objective in the research was to clarify the possible benefits of representing the Building Code as an expert system. A secondary objective was to study how easy it is to build this kind of expert system using commercially available tools.

The prototype system helps a designer to consider the Structural Fire Safety Regulations during the design process, and to check the compliance of the building with the requirements of the Building Code.

The knowledge is written into the knowledge base using the knowledge representation language of ES/P Advisor. The language seems to be suitable for logic programming, so also non-computer experts can build and maintain simple knowledge bases with it. 
The benefits of the developed expert system are:

- Expertise of using standards is always quickly available.

- The use of complicated standards is easier.

- The checking of the effect of combined standards is simplified.

- Possible logical faults in the standards are revealed.

3.1.4 What is needed to develop the prototype into a commercial product?

The Structural Fire Safety Regulations deal with details of buildings. There are a lot of restrictions for choosing structural elements, protective linings and surfaces. Materials are divided into special classes e.g. a structural element of the class A 120 must be made of noncombustible materials and its fire resistance time must be at least 120 minutes. Actually contractors or architects seldom know the fire classes of materials. Thus, it would be useful to integrate a database of materials into the expert system. This knowledge based system would also suggest suitable materials, instead of just showing the relevant regulations.

In practice it is of ten difficult to understand and use official regulations, because the language used in them is complicated jargon similar to law texts. Thus changes cannot be made in the text while writing it into the knowlegde base because every word can have a special and important meaning. But a knowledge engineer can add cases of acceptable design solutions into knowledge bases in the form of drawings and figures to make the knowledge more understandable. The drawings and figures can be digitized or scanned into a "photobase", which is integrated with the knowledge base. For each regulation there can be a clarifying picture to which it references.

The delivery of the expert system can be made in two ways: using a centralized databank or distributing runtime versions to end-users on diskettes or on laser optical discs. The former is $a$ better solution if the knowledge base is large and complicated and must of ten be updated.

\subsection{Expert system for repainting of wooden facades}

At a research institute, such as the Forest Products Laboratory of VTT, there is a lot of knowledge about painting and repainting of wooden surfaces. However, the actual repainters, house and cottage owners, aren't very well acquinted with the problens of repainting. In order to try to relieve this problem an expert system was developed. The aim with the system has been to develop an easy-to-use aid for the common man who is confronted with a repainting problem. At this initial stage the system only considers wooden facades, complicated cases like windows and doors were left outside the system. An expert system was judged to be valuable for its ability to provide deduction from previously given answers (also indirect) and for possibilities with linking it to a database containing information about current paint brands.

In the repainting of wooden facades there are two major problems. The first is to recognise all the types of deterioration phenomena that are evident in the case and the second is to determine the type of the previous paint. Deterioration can be divided into three major categories: normal deterioration, unnormally quick changes and other cases (e.g. repainting to change the colour of the house). As different phenomena are found to be true the system gives advice on how to deal with these cases. After this the type of the previous paint is ascertained, which determines which types of paint can be used in the repainting. The user is shown a list of these paint types and also a list of corresponding commercial paint brands and their manufacturers. All the pieces of advice given and the paint lists can be printed on paper at the end of the consultation.

The system was initially based on a simplified flow chart where connections between major sections were explicitly stated. The knowledge engineering was carried out in the Laboratory of Building Economics, while the expertise was provided by the Forest Products Laboratory. Originally the system was built on ES/P Advisor expert system shell, but later on the whole system was transferred to the Insight-2 shell. The main considerations for this were the better connections to other programs and databases in Insight, its convenient way of representing knowledge 
and higher speed of execution (a compiled knowledge base instead of an interpreted one).

As the system was already to some extent implemented on one shell, the conversion to another shell took much less time than the first transformation from the experts' knowledge to rules in the knowledge base. To develop the first ES/P-version took more than two months, the direct conversion to Insight about two weeks and the later enlargement and upgrading then again more than a month. The present system contains about 70 rules. The external functions (database and file handling, printer output) are programmed with Turbo-Pascal.

A major problem has been how to determine the type of the previous paint on basis of only those observations a common man can be expected to be able to do. The problem has not yet been quite satisfactorily solved.

The present system is only a prototype. A fully developed system could be used for example in a paint store. There it would be used by the customers who have come to buy paint for their houses. It could also be used in construction information centres for giving advice on different kinds of repainting problems. This system would then include all different kinds of outdoor wooden surfaces (i.e. facades, doors, window frames etc.). Another direction for the development is to use this kind of expert system for management of scattered scientific knowledge about painting at the Research Centre.

So far the development process has been valuable in giving information about the possibilities of expert systems in painting problems. Experience has been gained on how to link expert systems with external programs, databases and datafiles. Also evaluation of the different expert system shells and their possibilities has been useful. The project has shown that the present shells can already be used for these kind of small advice giving expert systems.

\subsection{A knowledge based system for pavement design}

A typical pavement is constituted of an asphalt concrete surface, a bider layer, a granular layer and a granular sub-base layer. A lot of experimental knowledge is needed for designing that structure. Because of the vast number of potential solutions, the design demands expertise of many professionals.

The pavement design process consists of three phases. These phases are the analysis phase, the synthesis phase and the evaluation phase. The analysis phase includes establishing environmental conditions, expected traffic volumes and performance criteria. The synthesis phase includes discovering candidate pavement structure solutions. Especially in this phase a lot of experimental knowledge is needed. In the evaluation phase the pavement structures must be evaluated against various criteria, such as economic and structural capacity.

A small prototype knowledge system for road pavement design has been developed. This system is based on official Finnish pavement design guidelines.

Insight-2 expert system shell has been used for building this knowledge based design system. It was interesting to notice that the building of a design knowledge system was possible even though the shell is especially meant for diagnostic expert systems. The calculation parts were programmed using the Pascal programming language. These calculation parts are integrated with the knowledge base and can be called from the knowledge base when needed.

A great benefit provided by the system is the expertise of pavement design that is codified in it. This expertise assists the pavement designer in the design process (Figure 1). Especially experimental knowledge is contained in the module for coping with the synthesis phase. In this phase the system presents possible solutions. The user of the system can make changes to the structure suggestions and the user makes the final decision on the most useful pavement structure candidate. Some calculations for optinizing thickness of layers are performed after the selection of the most useful pavement structure. In other phases guidance is also given. 
It is possible that even a person who is not an expert in the road construction area can manage to design pavement structures using this system. In the future this knowledge system could be used:

- For training students of civil engineering.

- On road construction sites. Often designs have to be changed and a road designer is not available.

- In design firms.

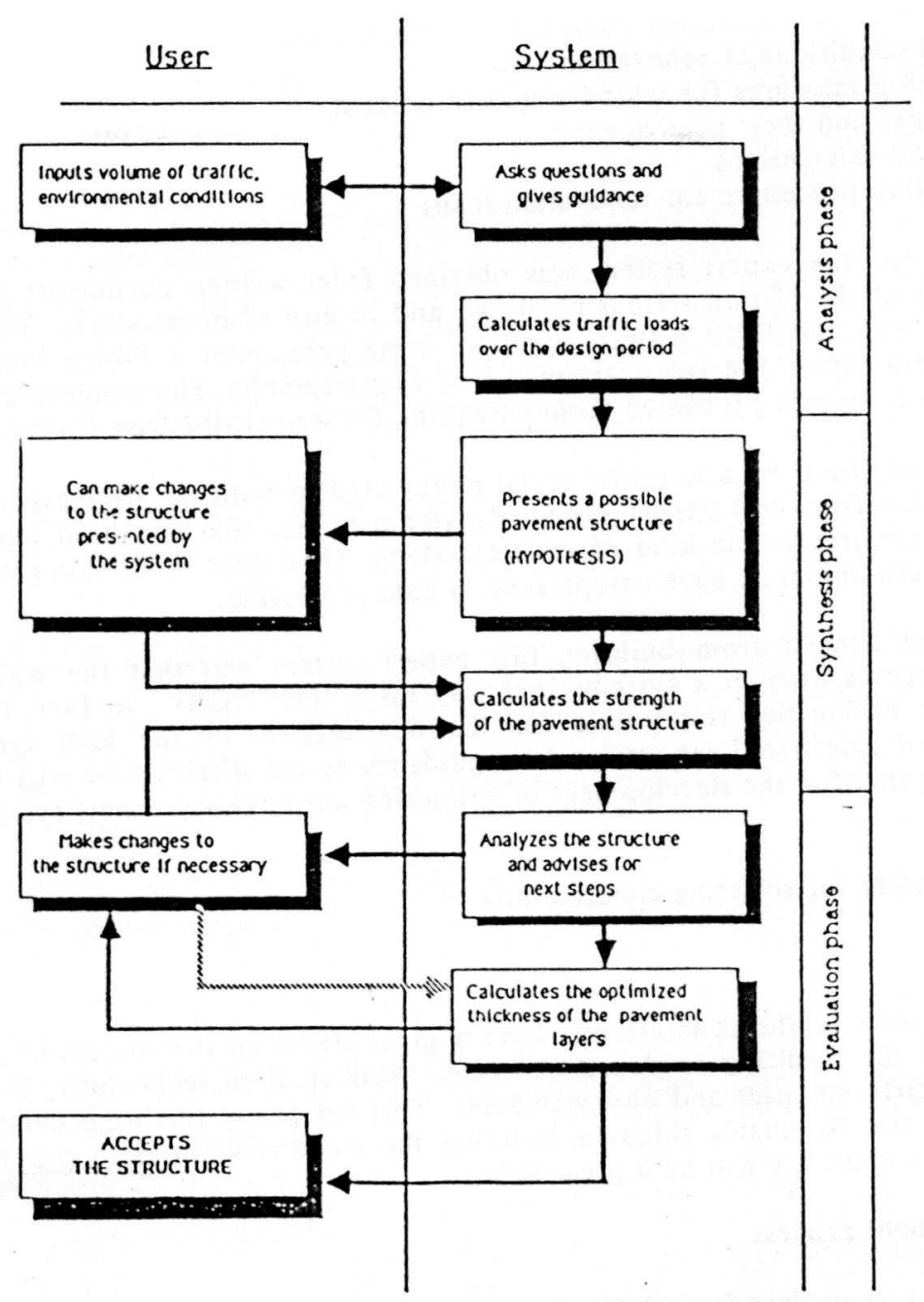

Figure 1. Use of the pavement design knowledge system.

3.4 Expert system for renovation loan guidance

The current renovation loan system in Finland is very complicated, and it is changed almost yearly. Because of that it is not easy for the citizens to understand the loan system or in 
general to get information about it. This was a major empiric result in a research project into renovation problems, realized by the Department of Social Policy of the University of Tampere [Hynynen 1985]. This was the background for experimenting, how an expert system could help the dwellers to get more information.

In principle, the expert system helps the user to look over the conditions of renovation loans and to find out his own possibilities to get a loan. The demonstration expert system was constructed for a part of the renovation loan system. It concerns loans for the owners of houses which have less than three dwellings, which is the most common type.The following subjects are dealt with:

- information on renovation loans and other subsidies

- general conditions of renovation loans

- renovation measures for which loans are granted

- loan types and their prerequisites

- plans and calculations

- application procedure for renovation loans

Knowledge for the expert system was obtained from written documents and from interviews with experts at the National Housing Board and in city administrations. The expert system was constructed with the ES/P Advisor shell. In some paragraphs a Prolog interface was used. In all, the system covers 154 rules, grouped into 24 paragraphs. The memory capacity limitation of the early ES/P version prevented from extending the knowledge base further.

The system was built by a last year social policy student with no prior experience in computing. One conclusion from this expert system development was that one need not to be a knowledge engineer to construct some kind of expert system. Of course this doesn't apply for large applications, where one must have competence in data processing.

An additional benefit from building this expert system was that the whole renovation loan system was represented in a systematized way (as a flow chart). In fact, this had never been done by the authorities responsible for the development of the loan system. The National Housing Board considered renovation loan guidance as too difficult an area for a useful expert system, but opted for the-development of a housing aid advisory expert system, to be started in 1986.

\subsection{Expert system for selecting concrete mix}

\subsubsection{Problem}

The characteristics of the concrete mix have a great effect on the success of concreting and for the quality of the resulting hardened concrete. With modern technology, it is possible to mix concrete for different uses and environments. This versatility sets high demands on the designer's and the site foreman's skills in selecting the right mix for each purpose. This is where expert system technology can be a great help.

\subsubsection{Development process}

The expert system project for selecting concrete mix started in late 1985. A similar project is also going on at the NBS in the United States [Clifton 1985]. The project is carried out in cooperation by the Laboratory of Building Economics (BE) and the Concrete and Silicate Laboratory (CS). A guide for concrete selection has already been written in the CS-laboratory, with the aid of the biggest construction firms in Finland. Accordingly it contains well approved solutions for the problem and is thus a good basis for expert system development.

The development work started with a study of the relevant parts of the selection guide. The knowledge in the guide is transformed into a representation suitable for an expert system. In this project it means using decision tables and production rules. A decision table is a clear way to represent knowledge, but it also has its restrictions. The number of tables increases fast 
with the number of knowledge items. Also hierarchical dependencies among knowledge items are difficult to represent.

When the knowledge has been represented in a way independent of the actual tool used for coding it into the knowledge base, it is presented to the expert for the first time evaluation. This is to ensure that there are no severe faults in the knowledge before starting the coding.

In the first version it is more important to test the functionality of the expert system than to make the system efficient. So it was decided that an expert system shell should be used instead of programming languages, such as Lisp or Prolog. The shell chosen for the project is Insight 2.

\subsubsection{Architecture of the system}

The programming of the knowledge base has just begun so there are no definite descriptions of the outcome. The expert system building process is, as known, very much prototype oriented work. But some of the main ideas have already been fixed. The inteference mechanism will be backward chaining with additional forward chaining to volunteer the initial data for the system. The knowledge representation scheme will be production rules with simple attributes and their values in the rules. A great deal of the knowledge will be put in explanatory statements to ciarify the questions and conclusions. The selection of concrete mix is seldom a deterministic process, so the system will include some kind of fuzzy logic. This is realized by using certainty factors with attribue values and rules. But at the beginning, inferencing will be handled deterministicaily for making the verification of the knowledge base easier.

Figure 2 shows a cu:tple of lines of code written with Insight 2. The syntax is very readable.

RULE Determination of concrete plasticity 1

IF Foundation IS Footing on ground

AND Footing IS Wall footing

AND NOT Pump casting

THEN Plasticity is $3 . .5 \mathrm{sVB}$

RULE Determination of concrete plasticity 2

IF Foundation IS Footing on ground

AND Footing IS Pillar footing

AND NOT Pump casting

AND Reinforcement IS Dense

THEN Plasticity is $2 . .3 \mathrm{sVB}$

Figure 2. An example of the syntax of the knowledge representation language of Insight 2 . The example contains two rules for determining of the concrete plasticity for foundations.

The example also shows one of the drawbacks of pure production rules: even if there are common parts in the rules, they cannot be written only once, but must be replicated for every rule.

\section{Conclusions}

On basis of the experimental expert system development work carried out in the Laboratory, we are quite confident that knowledge based systems will rapidly proliferate in the construction industry, as in other industries and spheres. The best of the commercial expert system shells available by the end of 1985 are quite suitable for building small intelligent job aids. In 1986, the next generation of shells, with linkage to popular integrated spreadsheet software, will be available. By means of them, totally new applications will become possible.

Knowledge engineering has proved to be a multi-faceted innovation. In addition to storing and 
distributing knowledge, its original mission, knowledge engineering seems to be applicable in interfaces of ordinary programmes and as a programming method. Thus, knowledge engineering will probably integrate with conventional programming.

The basic ideas of knowledge engineering are not too complicated; however, they are powerful. Knowledge engineering literacy for everyone is not an exaggerated renuirement. Experimental work on expert systems is suggested to all organizations with substantiai data processing activities and computer professionals.

\section{REFERENCES}

Allwood, R.J. \& al. Report on Expert System Shells Evaluation for Construction Industry Applications. Loughborough University of Technology, Department of Civil Engineering. August 1985.

AMUBC-systems. Final report. Department of Architectural Science University of Sydney, NSW Australia 2006, August 1984, 75 p.

AMUBC-systems. Users reference manual. Department of Architectural Science University of Sydney, NSW Australia 2006, August 1984, 35 p.

Björk, B-C.: Computers in the British contruction industry. Valtion teknillinen tutkimuskeskus, tiedotteita 431, Espoo 1985, 49 p.

Clifton, J.R. et.al. Development of Durcon, An Expert Sysiem for Durable Concrete: Part I. U.S. Dept. of Commerce, National Bureau of Standards, July 1985. 22 p.

Harmon, Paul \& King, David. Expert Systems. New York, Wiley, 1985. 283 pp.

Harris, J.R. \& Wright, R.N: Organization of building standards: systematic techniques fos scope and arrangement. National Bureau of Standards, Building Science Serves 136, Washington D.C. Sep.1981, 228 p. + app. 39 p.

Huomo, Tapio. Asiantuntijajärjestelmäkehittimet mikrotietokoneilla. TT-Innovation Oy. Lokakuu 1985 .

Hynynen, R. Asiantuntijajärjestelmä perusparannusneuvonnan apuna. Tampereen yliopisto, sosiaalipolitiikan laitos, tutkimuksia 75, Tampere, 1985, 57 pp.

Koskela Lauri. Construction Industry towards the Information Society - the Japanese Example. Laboratyry of Building Economics, Technical Research Centre of Finland, November 1985, FACE Report No. 7.

Lansdown, John, Expert Systems: Their Impact on the Constrüction Industry. RIBA Conference Fund, 1982. $106 \mathrm{pp}$.

McCarthy, J.: Logic at a Glance I - III. Computer Language, JULY - SEPTEMBER 1985.

Rehak, Daniel. Expert Systems in Construction and Construction Management. In: The Use of Computers in the Construction Industry, Budapest 1985, pp. 160-175.

Stahl, F.I. et al: Expressing standards for computer-aided design. Computer-aided design 1983:6 pp. 329-334.

Wager, Denis. Expert Systems and the Construction Industry. Construction Industry Computing Association. October 1984. $128 \mathrm{pp}$. 
Lauri Koskela, Raija Hynynen, Martti Kallavuo, Kalle Kähkönen, Jouni Salokivi

Laboratory of Building Economics

Technical Research Centre of Finland

Itătuulentie 2

02100 Espoo

Finland 